\title{
A Phenomenological Study of Sexuality among the People of Tutu Akuapem-Ghana: Implications for Comprehensive Sexuality Education (CSE)
}

\author{
Solomon Kwame Gyamerah'1 \& Maxwell Kojo Tsibu' (iD \\ Methodist College of Education, Akyem Asene-Aboabo, Oda-Eastern Region, Ghana.
}

\begin{abstract}
Issues about human sexuality have generated serious discussion in both public and academic discourses. In Ghana, the recent frightening figures of teenage pregnancy and diverse reactions to homosexuality, gay, bisexual, and transgender in news outlets have heightened the exigency of sexuality deliberations among religious, political, human rights activists, and social commentators. Amid the controversies and difficulties surrounding sexuality matters, the question is how do Africans maintain their 'Africanness' in search of expanded understandings and pedagogies of sexuality? Which indigenous conventions and rites must be interrogated to have the 21stcentury African child well informed and equipped to deal with his/ her sexuality? Using the phenomenological approach, the researchers sought to examine indigenous sexuality rites and norms of the people of Tutu Akuapem Community in the Eastern region of Ghana, focusing on puberty and marriage rites of passage. The study argues for a carefully thought-out compromise between custodians of indigenous values of sexuality and modern theorists and activists for new(er) ways of conceiving, expressing, and teaching sexuality. It recommends that the content of the newly designed curriculum of sexuality education in our schools must be adapted to reflect African worldviews, values, and customs of sexuality.
\end{abstract}

Correspondence

Solomon Kwame Gyamerah

Email: rev.gyamerah@gmail.com

Publication History

Received 10th June, 2021

Accepted 13th July, 2021

Published online 22nd July, 2021

Keywords: Sexuality, Gender, Phenomenology, Comprehensive Sex Education, Rite of passage

(C) 2021 The Author(s). Published and Maintained by Noyam Publishers.

This is an open access article under the CCBY license (http://creativecommons.org/licenses/by/4.0/).

\section{INTRODUCTION}

The subject of sexuality and rites of passage has reappeared in the media among religious, political and human right activists, and social commentators in recent times. There are sustained debates, comments and advocacy of many kinds on sexuality on mass, print, electronic and social media platforms.

In a broad sense, 'human sexuality refers to the gamut of human sexual experience (biological, social, cultural and psychological), and the gamut of human sexual expression, otherwise referred to as the expression of sexuality. ${ }^{1}$ Basic concepts which play vital roles in the sexuality discourse include sexual awareness, thoughts, feelings, experiences and expression or behaviour. ${ }^{2}$ Sexuality involves certain developments that are closely related to individuals as well as their interactions with others in society.

Concerning the individual, the critical factor in sexuality is the production of desire and procurement of or participation in sexual activity which involves initiation, negotiation, reciprocation, rejection,

\footnotetext{
1 Tawio Oloruntoba-oju, "Sexuality Language and Communication in Africa," Sexuality in Africa Magazine \& Monographs, 7(2), (2011): 2.

2 Oloruntoba-oju, "Sexuality Language and Communication in Africa," 2.
} 
participation, severance or dis-engagement. Beyond the individual, society institutes "discourses" or language whose aim or import is to "govern" the community's behaviour. Therefore, these forms of discourse reflect the power relations of society over time while also reflecting different regional and or cultural constructions of sexuality. It means sexuality is perceived as part of a society's ethical or moral precepts, which may involve taboos, rules and practices. Hence, cultural mediation of sexuality occurs mainly at the level of language and associated interpretations, mores, laws, and practices, all of which are determined by socio-cultural perceptions of sexuality and gender relations. Both sexual predilections and cultural taboos are thus represented in language and influence sexual communication.

Although there seems to be a "universal" language in the global world for expressing sexualities, namely, homosexuality, heterosexuality, bisexuality, bestiality, etc., different ethnicities, societies, and social groups have different ways of coding and expressing sexuality. ${ }^{3}$ When it comes to rights and rites related to sexuality, there exists cultural relativism based on particular moral codes, worldview, and legal restrictions in dealing with it and communicating it. Again, many parents and religious and traditional leaders find unacceptable the teaching of Comprehensive Sexuality Education (CSE) to children at the lower levels of education. ${ }^{4}$ Among other factors, people have not examined the complete picture of sexuality and its related questions; others also think the CSE curriculum is part of a grand agenda seeking to impose an alien worldview on sexuality upon the African people.

Against this backdrop, this paper argues that indigenous values and norms on sexuality should be evaluated and updated in the light of a formal education curriculum that seeks to curtail the challenges confronting children, adolescents, and society at large on sexuality matters. It also argues that traditional and religious leaders should be directly involved in designing any comprehensive curriculum aimed at addressing sexuality challenges.

This, the authors argue, is the best way to reach a pragmatic compromise between tradition and scientific knowledge since sexual activity is an important social value in African soceities that is strictly guarded by societal codes of behaviour. The arguments of the paper are developed under the following sub-themes: (1) Conceptual clarifications on sexuality, sex and gender, (2) a brief background to the Tutu Akuapem Community, (3) meaning of sexuality in Tutu Akuapem Community, (4) elements of sexuality in puberty rites, (5) aspects of sexuality in marriage rites, (6) traditions and taboos of sexuality, (7) perceptions on Comprehensive Sexuality Education (CSE), and (8) overcoming challenges associated with CSE in Tutu Akuapem Community.

\section{METHODOLOGY}

This study falls within the qualitative paradigm. ${ }^{5}$ The population of the study comprises the elderly people and youth of Tutu Akuapem, Eastern Region - Ghana. Tutu Akuapem is chosen for this study because of the notion it is one of the few communities in Ghana which still adhere to indigenous traditions regarding sexuality. The purposive sampling technique was adopted to sample respondents from the community of Tutu Akuapem. In all, a total of 30 people (i.e., 15 elders and 15 youths) were purposively sampled for the study. Interview, observation and focus group discussion were the methods employed to collect primary data. An interview guide with open-ended questions was the main instrument for data collection. Retrieved data were presented and analysed using themes. Analyses of the primary data were substantiated with existing literature on sexuality, sex and gender. To take a critical look at sexuality in an indigenous community as 'cultural insiders' and 'religious outsiders, ${ }^{6}$ the researchers were guarded by the assumptions of the phenomenological

\footnotetext{
3 Eric Anum, "The Body Matters: Rights and Rites of African Sexualities and the Body in the context of 1Cor. 6." International Journal of Humanities Social Sciences and Education (IJHSSE), 1(8), (2014), 99-100.

4 Facing the facts: the case for comprehensive sexuality education. UNESCO Policy Paper 39, https://en.unesco.org/gem-report/sites/gem-report/ files/CSE_references.pdf

5 The study deals with a qualitative phenomenon (i.e., sexuality and rites of passage) within the natural setting to understand human behaviour and the reasons behind such behaviour. See John W. Creswell, Research Design: Qualitative, Quantitative, and Mixed Methods Approaches (London, UK: Sage Publications Limited, 2010), 145.

6 Rosemary Amenga-Etego. Mending the Broken Pieces: Indigenous Religion and Sustainable Rural Development in Ghana, (Nairobi, Kenya: Africa World Press, 2011), 18.
} 
approach. $^{7}$

Phenomenology proceeds by "seeing," clarifying, and determining meaning, and distinguishing meanings. It does not theorize nor carry out an explanation in the sense of deductive theory. ${ }^{8}$ This method has both philosophical and non-philosophical antecedents. ${ }^{9}$ It explain concepts and propositions on their own terms. Its focus and principles are distinct from those of the natural sciences. It privileges insiders' views (the first person or subjective point of view) without reducing their experiences in biological, psychological, or sociological or "reducing" it to something else.

The phenomenological approach is apt for this study because its principles support descriptive and hermeneutics rather than prediction, control, and measurement. The data and underlying questions of the study are not amendable to quantitative or empirical methods. Phenomenology aids the researchers in investigating and become directly aware of a phenomenon in its immediate experience, thereby describing its essential structures.

This methodological approach is credited to Edmund Husserl (1859-1938). ${ }^{10}$ Husserl criticized psychology as a science that had gone wrong by applying methods of the natural sciences to human issues. Husserl seemed to believe that researchers who attended only to external, physical stimuli that could be isolated and correlated with other isolated responses not only missed important variables but ignored context and created a highly artificial situation. In this sense, the phenomenological method is the surest way to arrive at true meaning through penetrating deeper and deeper into reality. ${ }^{11}$

The phenomenological method accurately describes how appearances manifest themselves in human experience and their essential structures. It is also characterised by antireductionism. Phenomenology frees researchers from unexamined presuppositions, guards against causal explanations to be able to describe that which appears and to intuit or decipher essential meanings. It emphasises the world as lived or experienced by a person, not the world or reality as something separate from the person. ${ }^{12}$ This inquiry asks, "What is this experience like?" as it attempts to unfold meanings as they are lived in everyday existence. Donald E. Polkinghorne ${ }^{13}$ identified this focus as trying to understand or comprehend the meanings of human experience as it is lived. The 'life world' is understood by Edmund Husserl as what humanity experiences pre-reflectively, without resorting to categorization or conceptualization, and quite often includes what is taken for granted or those things that are common sense. ${ }^{14}$ The study of these phenomena intends to return and re-examine these taken-for-granted experiences and perhaps uncover new and/or forgotten meanings.

In line with Husserlian transcendental phenomenology, the researchers have chosen to remain objective and neutral to the intentionality of the phenomenon under study through the use of

\footnotetext{
7 Numerous scholars such as Gerardus van der Leeuw (1890-1950), Joachim Wach (1898-1955), C. Jouco Bleeker (18981983), Mircea Eliade (1907-1986), and Jacques Waardenburg (b. 1935) categorise the phenomenology of religion as a specific discipline, or method within Religionswissenschaft.

8 Etymologically, phenomenon and phenomenology are derived from the Greek word phainomenon (i.e., that which shows itself, or that which appears).

9 In non-philosophical sense, the phenomenologist describes but does not explain, the nature of religious phenomena; he/she assembles groups religious phenomena to disclose their essential aspects so as to formulate typologies. The German philosopher Immanuel Kant (1724-1804) devoted considerable analysis to "phenomena" as the data of experience, things that appear to and are constructed by human minds. Such phenomena, which Kant distinguishes from "noumena," or "thingsin-themselves" independent of our knowing minds, can be studied rationally, scientifically, and objectively. Hegel disputes Kant's phenomena-noumena bifurcation and argues that phenomenology is the science by which the mind becomes aware of the development of Spirit and comes to know its essence - that is, Spirit as it is in itself - through a study of its appearances and manifestations. See, Olof Pettersson and Hans Akerberg, Interpreting Religious Phenomena: Studies with Reference to the Phenomenology of Religion (New York, Atlantic Highlands, 1981), 17.

${ }_{10}$ Tech Koch, “The Influence of Husserl and Heidegger,"Journal of Advanced Nursing, 21, (1995): 827-836.

11 Phenomenology, in this sense, was seen as a movement away from the Cartesian dualism of reality being something 'out there' or completely separate from the individual. 'Interpretive approaches in nursing research. See, Tech Koch, "The Influence of Husserl and Heidegger,"827-836.

12 Ronald Valle, Martin King, \& Steen Halling, “An Introduction to Existential Phenomenological Thought in Psychology,” In Existential-phenomenoligical perspective in psychology, ed. Ronald Valle \& Steen. Halling (New York: Plenum Press, 1989), $3-16$.

13 Doanld E. Polkinghorne, Methodology for the Human Sciences: Systems of Inquiry (Albany: State University of New York Press, 1983), p. 109.

14 Edmund Husserl, The idea of Phenomenology (The Hague, The Netherlands: Nijhoff, 1970), 85.
} 
phenomenological epoché. By this principle, the researchers bracketed the uncritically accepted "natural world" through suspension of beliefs and judgments based on an unexamined "natural standpoint" to become aware of the phenomenon of immediate experience and gain insights into its essential structures. This principle equips the researchers to become attentive to a much fuller disclosure of what manifests itself and how it manifests itself in experience; it allows for greater awareness of phenomena experienced on pre-reflective, emotive, imaginative, nonconceptual levels of intentional experience, thus leading to new insights into the specific intentionality and concrete richness of experience. Research empathetic attitude towards the experiences and rituals of the subject of the study would be allowed to undermine the 'otherness' of the researchers. Thomas Jones challenges phenomenologists to extend their understanding of bracketing beyond a suspension of belief to the cultivation of doubt to help open one's self to the work at hand. ${ }^{15}$

In addition to that, the researchers set out to disclose the essential features of sexuality embodied in rites of passage of the Tutu people of Akuapem. This is informed by phenomenological insistence on the intuition of essences, often designated as "eidetic vision."16

One of the weaknesses of the phenomenological method is that it does not allow for intersubjective encounters among the actors (i.e., researchers and people being studied) to engage as epistemological "others" who seek to valorise pluriversal ways of knowing the world through experience. ${ }^{17}$ Again, the supposed principle of abstinence from value judgement in the exercise of empathetic participation is vague. There exists no scholarly criterion for verifying whether the doctrine of empathy has been achieved in a particular study. Again, it is practically impossible to rid oneself of all biases because a researcher is naturally an embodiment of his/her academic leanings and cultural traits and ideals. There is also the danger of biased description of the experience of the "other" since the subjects of the study are rarely given a chance to interrogate the researchers' own experiences and interpretations.

\section{Conceptual Clarification on Sexuality, Sex and Gender}

Sexuality is always discussed in the context of sex, gender and gender identity. Whereas sex usually refers to the biological aspects/traits of maleness or femaleness; gender implies the psychological, behavioural, social, and cultural aspects of being male or female (i.e., masculinity or femininity.); gender identity is one's self-identification as male or female. In other words, gender refers to the attitudes, feelings, and behaviours that a given culture associates with a person's biological sex. ${ }^{18}$ It is how humanity is socially constructed as male and female, in terms of their self-identity of one's personhood and expressiveness in terms of roles in societies, in terms of equality and justice.

While many people think of sex as biological and gender as social, this distinction is not clear-cut. The complex relationship between nature and nurture obviously implies that the point at which sex leaves off, gender begins. In almost all indigenous cultures, biological sex constitutes the basis upon which sexual orientations and gender roles are nurtured and assigned respectively. This corroborates with the famous words of Simone de Beauvoir: "Women are not born, they are made." ${ }^{19}$ Sex as the biological categories male and female, and people's understanding of themselves and others as male or female is ultimately social. Anne Fausto-Sterling sums this up in these words, "labelling someone a man or a woman is a social decision." ${ }^{20}$

\footnotetext{
15 Jones, W. Thomas, The Twentieth Century to Wittgenstein and Sarte (San Francisco: Harcourt Brace Jovanovich, 1975$), 42$.

16 From the Greek term eidos, it expresses the essential "whatness," the necessary features of phenomenon that allows one to recognise and different it from other phenomena. The deep or hidden structures of rite of passage-which are not apparent on the level of immediate experience — can be uncovered and decoded or interpreted through the eidetic reduction.

${ }^{17}$ Kofi Appiah has vehemently criticized Eurocentric and anthropocentric approaches to the material study of religion which always create an artificial binary of emic-etic and subject-object nexuses. These approaches are judged as 'exploitative epistemologies" which must be set aside for "liminal ethnography" as newest way of studying religion from material perspectives. However, this approach cannot be adopted for this study since it is still undergoing methodological conceptualization and testing. See, Kofi Appiah, Decolonizing Knowledge: Anthropocentrism and Cosmotheandrism in a world of Technologies (Groningen: CounterPoint Navigating Knowledge, 2020), 5.

18 American Psychological Association \& National Association of School Psychologists, Resolution on gender and sexual orientation diversity in children and adolescents in schools, 2015. (Accessed June 2, 2021)

Retrieved from http://www.apa.org/about/policy/orie ntation-diversity.aspx

19 The same is true of men.

${ }^{20}$ Anne Fausto-Sterling, Sexing the Body: Gender Politics and the Construction of Sexuality (New York: Basic Books, 2000$), 3$.
} 
Gender is, therefore, "not something we are born with and not something we have, but something we do"21 " "something we perform." ${ }^{22}$ In other words, the making of a man or a woman is a never-ending process that begins before birth - from the moment someone begins to wonder if the pending child will be a boy or a girl. The ritual announcement at birth instantly transforms an "it" into a "he" or a "she." ${ }^{23}$ This attribution is further made public and lasting through the linguistic event of naming ceremonies and other rites of passage.

Early linguistic acts set up a baby for life, launching a gradual process of learning to be a boy or a girl, a man or a woman, and seeing all others as boys or girls, men or women. Names and clothing are just a tiny part of the symbolic resources used to support a consistent, ongoing gender attribution even when children are clothed. Being a girl or being a boy is not a stable state but an ongoing accomplishment, something that is actively done both by the individual so categorised and by those who interact with him/her in the various communities to which he/she belongs. ${ }^{24}$

The maintenance of gender categories depends on reinforcement in day-to-day behaviour. Male and female could not persist as structurally important social categories if mankind did not perform enough gendered and gendering behaviour - if distinct groups of people did not continue to act like "women" and like "men." Rite of passages is one distinct group of social practice that emphasises the conventional aspects of sexuality and its relation to the broader social structure.

Gendering affects the physiological expression of sexes in society. The gendered male or female faces limited possibility for actions outside of 'meanings' already socially established. Social ideals and rituals exert some considerable influence on the expression of one's sexual identity. Like gender, issues of sexuality are shaped by societal values. ${ }^{25}$ Indigenous societies have elaborate norms and rituals which are meant to instil appropriate manners on sexual preferences and expressions.

\section{Who are the Tutu Akuapem?}

The people of Tutu Akuapem form part of the Akan ethnic group; they are a subset of the Akuapem people in the Eastern part of Ghana. Akuapem Twi language is their indigenous tongue. The community is located in the northwest part of Ghana. In one of their myths, the people of Tutu pride themselves as the first settlers (i.e., $k J b o t^{t e t e^{26}}$ ) on the Akuapem Ridge. Oral history further revealed that during official gatherings, they usually pride themselves with the appellation, "Tutu Akuapem, a people whose ancestral home' [i.e., place of origin] cannot be traced, who pre-existed before the settlement and formation of the 'Okuapemman. ${ }^{27}$ Diachronically, the original name 'kobo tete' became corrupted to kobo tutu, hence the name 'Tutu Akuapem.' This notion is expressed in a historical myth often narrated to explain their origin and present location.

According to the myth, two people, a man and a woman with a bible in their hand came from the skies in a large tray ${ }^{28}$ and settle in the town, then a forest. The bible in their hand raises a lot of questions. Some of these questions include "who were they?" "Were they Christian converts?" "If they were Christian converts, were they slaves who have been converted to Christianity by their slave masters?" Again, looking at the period during which this might have occurred (1700's), can it be postulated that Christianity to Akuapem ridge seems to predate the advent of Basel mission to Akuapem? These are reflections that cannot be resolved by this study but need further investigation. The mythical figures are said to be the progenitors of the people of Tutu-Akuapem. Through inter-marriages and socio-economic activities with neighbouring villages, the primitive figures

${ }^{21}$ Candace West and Don Zimmerman, "Doing gender." Gender and Society, 1 (2000), 25-151.

22 Judith Butler, Gender Trouble: Feminism and the Subversion of Identity (New York and London: Routledge, 1990).

23 Judith Butler, Bodies that matter (New York and London: Routledge, 1993).

${ }_{24}$ Penelope Eckert and Sally McConnell Ginet, Language and Gender (Cambridge and New York: Cambridge University Press, 2019), 8.

25 Oloruntoba-oju, "Sexuality Language and Communication in Africa, 2.

26 Kobo tete literally means, 'created of old' or 'people of old.'

27 The appellation is captured in the Akuapim language as "Akuapem man no ba\& no na Tutu woho dedaw, a wonnim nea wofi bae."

28 According to one of the respondents, the act of the descending basin is described as 'Ayowa a nkonsonkonson kura mu.' The Ayowa is said to be a very large basin and the 'nkonsonkonson' are the chains. In recent times during funerals, small type of the tray is used by widows to display all sort of items as presents to the family of the bereaved spouse. This ayowa is diffrerent from the apotoyowa (earthenware) also known by some Akans as asanka. 
established the present town of Tutu Akuapem. Currently, Nana Appiah Anti IV is the tenth chief of the Tutu Akuapem Traditional Council.

The people practise a patrilineal system of inheritance. Given this system, there is much interest in male children. In fact, anytime a male child is born, there is much joy and several congratulatory messages ${ }^{29}$ sent to the woman. Informants of the study indicated that the level of elation and congratulatory messages that are expressed in a situation when a female is born into the family is not the same. In terms of economic life, they are predominantly subsistent and small-scale farmers. However, few migrants, primarily teachers, nurses, and technicians, have found themselves in the community either due to employment or accommodation. According to one of the linguists interviewed, there is a great sense of communalism among the people because each family seems to have an ancestor who emanates from the other family. This may account for their flexibility in marriage.

The major festival of Tutu- Akuapem is Ohum. This annual ritual draws natives from all the corners of Ghana to celebrate their rich heritage, customs and culture. Apart from inheritance, economic activities, indigenous medicine and health practices, the people of Tutu Akuapem have a peculiar understanding of sexuality. The next two sections of the study bring to fore the conceptualisation and expression of sexuality in puberty and marriage in Tutu-Akuapem.

\section{The Meaning of Sexuality in Tutu Akuapem}

Sexuality is a broad concept among the people of Tutu Akuapem. There is no term or concept in Akuapem or other Akan languages which fittingly translates 'sexuality. Figuratively, the people of Tutu Akuapem describe 'sexuality' as, obea ne sbarima bobea ne agoro a wode' or 'oba ne sbarima agoro ne asetena mu nsem,' which can be summarised literally as 'the relationship between the male and female.' It connotes the sexually related aspects and activities of human life guided and preserved by social customs and taboos.

One observes that the people of Tutu Akuapem understand sexuality as a diverse phenomenon which occurs in different physical locations and social contexts and consists of a wide range of activities, from birth to death. They do not conceptualise it only in terms of sexual activity and procreation. More importantly, they see sexuality as how the opposite sex relates with each other with regards to their affections and emotions which eventually determine who they are and what they must do or not do in their community.

This description of sexuality among the Tutu Akuapem agrees with James Nelson and Sandra Longfellow's assertion that "while sexuality may include our desires for experiencing and sharing genital pleasure, it is far more than this. More fundamentally and inclusively, it is who we are as bodyselves - selves who experience the ambiguities of both "having" and "being" bodies." ${ }^{30}$ Nelson and Longfellow go on further to say that "sexuality includes a range of feelings, interpretations, and behaviours through which we express our capacities for sensuous relationships with ourselves, with others and with the world." ${ }^{31}$ It constitutes a fundamental part of their existence as a human society; it involves feelings, wills, memories and self-understanding as embodiments of their personhood. Although sexuality is not confined to acts of sex, the people of Tutu Akuapem have elaborate norms and taboos on sexual parts and sexual issues.

Sexual parts moderately determine the masculinity and femininity features of the people. At puberty, the physiological and hormonal changes in adolescents are termed 'adolescent sexuality.' Despite being sexually active, adolescents are prohibited from engaging in sexual acts since societal norms of the people frown on it. The sexual parts of the adolescent are meant to be preserved for sexual acts when one has attained the societal age of an adult. Only in marriage does sexuality attain the fullness of its social value in many African communities. Sexuality was not spoken about except in connection with marriage. The notions of Tutu Akuapem on these sexual parts, sexual acts and sexual issues are further described under puberty rites and marriage, the two dominant contexts of sexuality discourse and education.

\footnotetext{
29 ' $y \varepsilon n$ tiri $n k w a$ ' (i.e., life unto us) expresses their thankfulness for having their preferred wish established.

30 James B. Nelson and Sandra P. Longfellow, Sexuality and the Sacred: Sources for Theological Reflection (Louisville: Westminster/John Knox Press, 1994), 14.

31 Nelson and Longfellow, Sexuality and the Sacred: Sources for Theological Reflection, 17.
} 


\section{Elements of Sexuality in Tutu Puberty Rites}

Puberty rites for girls and boys are more or less one of the strong African traditions where young adults are taught socio-cultural expectations of their society and how to meet up with future challenges ahead. The rites are built on formal teaching in intiation ceremonies and on informal teaching through watching and imitating. The rationale is to encourage chastity before marriage in the community.

Before the rite takes place, there are some spiritual and material preparations that have to be conducted. The spiritual arrangement of the event involves finding out if the the girl's soul, locally known as "kra" conforms with the activities of the events. As for material preparation, it usually requires things like food items, money, chicken among others. While still in the separation mode, the girl to be initiated is presented to the queenmother who simply carries out an inspection to check if she is pregnant or not. Virginity is regarded as purity in the Tutu and all Akan communities and hence it is highly valued.

There is no elaborate education on sexuality at the childhood stage. It is instead at the time of puberty where adults of Tutu Akuapem train their youth about sexuality in connection with sexual maturity, manhood or womanhood. During the transition from childhood to adulthood, the community ensures that the sexual life of the adult-to-be is intact. Severe punishment is meted out to those who break the sexual taboos before the age of puberty. ${ }^{32}$ The rites deal essentially with the separation of the adolescent from the world and status of childhood and initiation and integration into adulthood. ${ }^{33}$ Thus, it is viewed as a period of separation, transition and integration.

In the traditions of Tutu Akuapem, puberty is a crucial stage in the life of the adolescent child, especially the female. Thus, any form of sexual activity before puberty is considered a deviation from the norms of the Tutu community. All the people interviewed revealed that pre-marital sexual activities are an embarrassment that every family, group of people or individual in the community would want to avoid. Becoming pregnant before puberty is seen as a sacrilege to one's family, and demands that the victim goes through some kind of rituals to prevent her from dying during her delivery. ${ }^{34}$

The female puberty rite known as bragoro is performed when the sexual organ and features of the adult-to-be begin to manifest. There is the manifestation of breast, broad bust, hips and thighs, pubic hairs and finally menstruation. Until puberty rites are performed, both the man and woman are seen not to be sexually developed and immature to marry. The rationale is to encourage chastity before marriage in the community. However, in recent times, cases of 'Eguamman' (sexual indecency), 'mprewa yinsen' (teenage pregnancy) and confused sexual identity in the Tutu Akuapem community and entire the Ghanaian society indicate that puberty rites alone cannot address all the contextual issues confronting the society. The pre-electronic society of Tutu-Akuapem did not experience many sexuality challenges among children, adolescents and adults. Globalisation and social media influences did not affect cultural norms on sex, sexuality and gender. Hence, indigenous knowledge and norms that parents and society impacted children and adolescents on sex, sexual activities, gender, and gender orientation did 'the magic' in their contexts. Currently, factors such as high level of technology, clash of cultures and ideologies, human rights activism, ethics of human freedom and autonomy the world is experiencing today have drastically changed and challenged indigenous understanding and expression of sexuality in every society. It is near impossibility for modern societies to rely only on taboos, indigenous norms, and the unsystematic informal education on sexuality to achieve its desired goals regarding how the $21^{\text {st }}$ Century child or adolescent is expected to conform to sexuality ethics.

The researchers observed some deficiencies in the Tutu Akuapem traditional curriculum on sexuality education. The indigenous society is a non-scripted one; ideals, principles, rules and maxims are stored orally and passed on from generation to generation. The series of activities that one must go through from childhood to adulthood to become well-informed about sexuality is bedevilled with a lot of loopholes. The foremost is the notion that sexual parts or organs should not be mentioned explicitly in public discourse or by a child before an adult. This convention inhibits children and adolescents from coming out with their multifaceted

\footnotetext{
${ }^{32}$ Nii T. O. Quarcopome, West African Traditional Religion (Nigeria, Ibadan: African University Press, 1987 ), 113.

33 Abraham Akrong, An African Philosophy of Religion (Ghana, Accra: Trinity Theological Seminary, 2006 ), 66.

34 Views of Kwasi. S. Sarpong and Okyeame Ani, Secretary and sub-linguist of Tutu Akuapem Traditional Council.

35 Teenage pregnancies recorded in 2020 in Ghana was over 100,000 cases. This number is more than the total number of COVID-19 cases that have been confirmed in the country since day one.

https://yen.com.gh/186213-teenage-pregnancies-recorded-2020-ghana-covid-19-cases-2020-2021-combined.html
} 
problems and questions. Today's children have the entire world before them, so they resort to other alternatives, particularly the media, to cope with their developmental challenges.

The interviewees disclosed that most teenage pregnancy cases emanate from illicit sex experiments among adolescents. Apart from the male circumcision and random instruction which parents give to their male children on sexuality, there exist no elaborate and democratic environment for young boys to discuss their curiosities and feelings about sexuality with their parents. They hide to engage in several practices that parents are not even aware of. The female children or growing teens find themselves in a web of confusing predicaments. They shy to tell their parents about sensitive issues which border on sexuality because the moment they do that, most parents would brand them as "nkwadaa no ase anaa nkwadaa bon" (i.e., spoilt or bad daughters). They live in a tense and authoritative environment where the courage and boldness to raise a topic on sexuality is impossible. In Tutu Akuapem, most adolescent girls receive their education upon having experienced menarche. Indigenous education is one-way; it is always in the form of 'dos' and 'don'ts' instructions. Rendered timid on sexuality, the adolescent girl cannot ask questions on her sexuality that have been troubling her all over the period.

\section{Aspects of Sexuality in Marriage Rites}

From the interviews conducted, it was observed that indigenous education on sexuality begins at the adolescent stage. However, debut sexual activity is prohibited until marriage. This means that sexual activities such as caressing, kissing, touching of another person's sex organs, penetration, or engaging in explicit romantic discourse are reserved for only those who have gone through the puberty rites and are married. Marriage is seen more as a transformative rite that symbolises the process of becoming parents and attaining societal recognition of that status. ${ }^{36}$ Technically, it is this period that affirms the sexuality of both the man and woman. Thus, although humans' biological anatomic determinants of sexuality are present at birth, it is only when a man impregnates a woman that they are considered as sexual beings.

In Tutu Akuapem traditions, marriage is contracted between the parents of the man and woman, sometimes, without seeking their consent. There are also cases where the families contract it through the consent of the man or woman, who might even be in courtship, 'mpenatwe. ${ }^{37}$ The marriage rite among the people which is almost similar to the Akan marriage rites entails the following three processes: (i) ase bisa (asking) (ii) followed by tiri-nsa and (iii) awaregye anaa sbaa ho ade ye (the ritual which climaxes the marriage rite). The ase bisa include nhuanianimu ${ }^{38}$ (declaration of intention to marry). This is the stage when the man's father approaches the father of the woman to inform him of their intention to marry their daughter, and then proceed to offer of nhuanianimu-nsa or kokooko bo (a bottle of Schnapp or any approved liquor with some amount of money). The acceptance of these items is an indication of consent and commitment of the woman's father to the marriage proposal. This paves the way for the man's father to proceed with the awaregye or ne ( a customary component of the awaregye and when performed, it gives the man and woman the permission to be recognised as husband and wife. ${ }^{39}$ Thus, the oral tradition reveals that in some circumstances the man is permitted to perform the ase bisa and tiri nsa and the couple are permitted to live together and even procreate.

Before the ase bisa is contracted, any sexual act or pregnancy at this stage is considered aguamman (an immoral act of fornication among the victims) and kwasiabu (a cheat) and enimguase (a disgrace) to the woman's family. In the case of a detected pregnancy, the marriage rite is withheld or suspended until the woman delivers and subsequently, determines the child's paternity. Another reason for the suspension of the marriage rite is the fear that the woman may lose the child during birth. But custom demands that the man offers some drinks and an amount to propitiate the woman's parents for the disrespect of not 'asking' for the woman's hand in marriage (i.e., kwasiabu). Sometimes the man's family is allowed to pay the kwasiabu sika, an

\footnotetext{
36 Akrong, An African Philosophy of Religion, 67.

37 'Mpenatwe' is the Twi word for courtship, which in recent times has been misconstrued for fornication. In Akan tradition, courtship means an intimate relationship without sex.

38 In the absence of the father of both the man and woman, their representative (nhuanianimu can be performed by an uncle or a close relative usually blood related relative of either of them.

39 Akwasi Agyeman Prempeh, Akanfos Amammers Comprehensive Notes on Oral Literature, Customs and Institutions for Students In Senior High Schools, (Ghana, Kumasi: Print House, May 2011), 98, 99.
} 
agreed sum of money, as compensation to the woman's family prior to the customary marriage rites.

As soon as this is done, the road becomes clear for the man's family to proceed with the kokooko and tiri-nsa. Once the knocking is accepted in the presence of selected members of the two families and a witness from the traditional council, the two parties (i.e., the man and the woman) can conveniently visit each other or live together under one roof as husband and wife and give birth to any number of children they wish until the man is adequately prepared to perform ' $2 b$ a ne ho ade\&/awaregye.' Usually after this point, it becomes the responsibility of the woman's father to impress on the son-in-law to come and complete the process.

Until the ceremony is completed, the man and the woman will continue to introduce themselves to others by the phrase, 'mene no na $\varepsilon w o ~ h \jmath^{\prime 40}$ which in Akan tradition is referred to as mpena aware. As a traditionally accepted form of marriage, mpena awares (cohabitation) is not a peculiar to the people of Tutu Akuapem. In a situation of the demise of any of the partners, the bereaved partner is not required to perform the rest of the marriage rite before the burial and funeral rites of the departed spouse. This is not so in other Akan cultures, where the bereaved man is obliged to perform all the marriage rites before gaining permission to perform the burial and funeral rites. Meanwhile, anytime the man expresses his intention not to continue the mpena awares he is required by indiegenous custom to perform sumkahyiar anaa akwankwagya as a compensation to the woman for wasting her time and for all services she has rendered.

Another aspect of marriage sexuality in Tutu Akuapem tradition is that men can marry more than one woman with the consent of and compensation for the present wife or wives. However, polyandry is not an acceptable norm for women. It is taboo for a married woman to express sexual desires towards another man or consent to the sexual expression of another man. When this happens, the man in question pays what is called 'ayere fari' (literally, a damage fee) to the woman's husband. Finally, the inability of either partner to prove his/her sexuality through childbirth sometimes constitutes a reason for divorce. According to a linguist interviewed, the parents of the woman have the right to seek divorce if the couple is found not to have given birth after some years.

One may argue that the indigenous sexuality manual on marriage has inherent deficiencies due to the patriarchal dominance in the marriage norms. For instance, a sexual request or act must not be initiated by the female. Irrespective of her rich insights or ideas that could help improve the sexual life of the marriage, the woman must keep quiet and submit. Doing otherwise is interpreted as being a 'spoilt woman.'

\section{Traditions and Taboos of Sexuality Among the People of Tutu Akuapem}

Cross-cultural studies on sexuality have established that all human societies regulate sexual behaviours and attitudes, though the details of these regulations vary significantly from one culture to another. ${ }^{41}$ Failure to provide balanced regulations, sensitisation, and comprehensive education on sexuality would lead to social disruptions with dire consequences on the quality of life, stability, and community development.

Tutu Akuapem community relies heavily on indigenous norms and taboos ${ }^{42}$ in regulating sexuality matters. A taboo is a prohibition against an item, person, or type of behaviour. Prohibitions against incest and marriage within certain groups are examples of behavioural taboos. Among the sexual taboos mentioned by the interviewees are incest, ${ }^{43}$ open sex, ${ }^{44}$ sex in sacred places like shrines, farms, bushes or beside rivers, sexual harassment, ${ }^{45}$ abortion, adultery with another man's wife, rape, prostitution, supisupi. ${ }^{46}$ A female respondent recounted a recent incident during the just ended Ohum festival at Mamfe Akuapem where the chief of the land commissioned his palace guards to drive away from the community group of men, suspected to be homosexuals. In all, these points buttress the level of seriousness at which the community detests what they consider as an inappropriate expression of human sexuality.

\footnotetext{
40 Cohabitation, in western parlance.

41 Janet Shibley Hyde and John D. Delamater, Understanding Human Sexuality (United States: McGraw-Hill Companies, 2000), 9.

42 A taboo is a prohibition against an item, person, or type of behaviour. In religious taboos, the forbidden item is believed to be unclean or sacred, and the taboo is imposed for protection against the item's power

43 Sexual activity between people of the same blood relations, knowingly or unknowingly

${ }_{44}$ Having sex or engaging in sexual activity in open places such as market places or behind houses, at the bank of river, etc.

45 Example, touching the waist beads of married woman.

${ }^{46}$ A common term used by (female) students in boarding schools in Ghana to describe the act of lesbianism.
} 


\section{Perceptions on Comprehensive Sexuality Education (CSE) in Tutu Akuapem}

Sexuality education is a curriculum-based process that aims to equip children and young people with knowledge, skills, attitudes and values that will empower them to: realise their health, well-being, and dignity; develop respectful social and sexual relationships; consider how their choices affect their own well-being and that of others, and, understand and ensusre the protection of their rights throughout their lives. (UNESCO, 2018, p. 26). CSE is rights-based, age appropriate and gender-sensitive education that covers six key concepts as per the international standard: (1) relationships; (2) values, attitudes and skills; (3) culture, society and human rights; (4) human development; (5) sexual behaviour; and (6) sexual and reproductive health. It includes the benefits of delaying sexual intercourse, while also providing information about normal reproductive development, contraceptions to prevent early pregnancies. CSE enables young people to protect their health, well-being and dignity. It also advances gender equaity and rights of empowerment of young people.

The transition from childhood to adulthood is saddled with health risk exposures related to sexuality and reproduction. Adolescent pregnancy and its associated health and social implications signify one of the major public health concerns that require critical resolution in many nations. In spite of these challenging sexual phenomena, many Ghanaians are uncomfortable with CSE being taught in schools. CSE curriculum has been heatedly lauded by religious and local leaders and the general public at large. A focus-group discussion with purposively sampled adults and traditional leaders of Tutu Akuapem revealed their difficulties, anxieties and challenges with the much-debated topic of introducing CSE curriculum at all levels of pre-tertiary schools.

However, many of the elders and adults of Tutu Akuapem view CSE as inappropriate for young children because it goes against their local cultural or religious values. It is said that it would cause 'gender confusion' and may be used to recruit young people into 'alternative lifestyles or non-conforming sexual orientation or gender identity. Their aversion towards CSE is also exacerbated by the uncertainty about what 'comprehensive' or 'sexuality' means in practice.

More specifically, the people of Tutu Akuapem are not comfortable with the exposure of tender children to knowledge about their sexual organs - which are held to be sacred. This is considered as a complete disregard and contempt of societal values and norms about sexuality. For them, matters or things about sexual organs such as the vagina, penis, testicles, breast, and buttocks as well as sex-related questions are not be discussed in the open setting. The fear of parents is that teaching adolescents issues on sexuality will empower adolescents to engage in sex earlier and more often than anticipated. Due to this, they prefer keeping adolescents on the dark side of certain forms of sexuality education. Related to this, some interviewees expressed the anxiety that teachers would end up corrupting children by teaching about sex and providing contraceptive methods.

When asked which elements should not form part of CSE, the members of the study indicated that topics such as sexual orientation, sexual practices, condom use, family planning methods, etc., are deemed 'immoral" and hence, must be avoided in the curricula. However, abstinence, chastity and marital sex must not only be taught but emphasized. A discussant referred to the ecstatic reaction the adults of the community expressed when the news broke that the Government has suspended the implementation of CSE at the early stages of primary education. This reveals the amount of backlash the people raised against the Ghana Education Service (GES) on introducing the sexuality education curriculum or content from lower primary schools. This expectation is underpinned by the socio-cultural and religious worldviews which dominate Africa's cultural plurality and complexity. ${ }^{47}$ How can CSE be promoted to sync with the socio-cultural worldview and values of specific traditional communities? The next sub-section offers various suggestions on indigenous notions and matters of sexuality that could be incorporated into the CSE curriculum to enable 21st-century children and adolescents to understand, appreciate, develop, own, and use their sexuality for the holistic development of human society.

\section{Relevance of CSE to Tutu Akuapem Community}

Recent indicators of sexual activities among adolescents, cases of teenage pregnancies, and HIV/AIDS prevalence points to the urgent need for CSE for adolescents across Ghana. CSE is an essential part of a

\footnotetext{
${ }^{47}$ Kofi Awusabo-Asare et al., From Paper to Practice: Sexuality Education Policies and their Implementation in Ghana,
} (Guttmacher Institute, 2017). (Accessed May 15, 2021)https://www.guttmacher.org/report/sexuality-education-ghana 
good quality education that helps prepare young people for a fulfilling life in a changing world. It is a curriculum-based process of teaching and learning about the cognitive, emotional, physical and social aspects of sexuality, going beyond the narrower indigenous approaches that were more common in the past. ${ }^{48}$

Among other things, the goal of CSE is to create a formal, democratic, tension-free and lively environment for children or adolescents to learn about a crucial aspect of life and get the right answers to curiosities and questions they have about their own sexuality. The rationale is to boost their self-esteem, to make them accept their body physique, and to make them confident about themselves so as to grow to become productive citizens. It aims to improve sexual and reproductive health-related outcomes, such as HIV infection and adolescent pregnancy rates, which in turn helps expand educational opportunities. It disrupts harmful gender norms and promotes gender equality, which helps reduce or prevent gender-based violence and hence creates safe and inclusive learning environments.

As an active teaching and learning approach centred on students, it helps develop skills such as critical thinking, communication and decision-making that empower students to take responsibility for and control their actions and help them become healthy, responsible, productive citizens. The discussions of sexualityrelated issues such as teenage pregnancy, sex myths, aphrodisiac or sex-related substances, dating or courtship, sexual orientations, rape, sex ethics, and civil laws on sex and sexuality would help adolescents make informed decisions and choices in life. This would make them more actively responsible for their sexualities than the passive posture indigenous norms and practices have put them. CSE furnishes the individual with the necessary information and understanding to build the proper attitudes related to desirable social responsibility and community living.

Internationally, CSE has become a key component of the adolescent's development and effective decision-making and the transition to adult life. In fact, the World Health Organisation (WHO) has reiterated that investments in adolescent health and well-being bring a triple dividend of benefits now, into future adult life, and for the next generation of children. ${ }^{49}$ This makes the teaching of comprehensive sexuality education, especially in secondary schools, not only critical but timely.

For the goals of CSE to be realised, parents must be educated (through civic education, community-based workshops) to remove barriers that inhibit children from asking sensitive questions about themselves or sexuality in general. The parent must disambiguate the minds of children about sexual parts or organs. They must be encouraged to accept or see the organs as an essential part of their body anatomy meant for specific functions at specific stages in life. While the child should be taught traditional ethics on human sexuality, they must also be encouraged not to shy away from that aspect of their personality. The reasons why ancestors held issues of sexuality in sacred esteem must be explained to children. However, the world has undergone rapid changes. Unlike the pre-technological age, today's children can easily access information from peers and the media that may not be reliable, accurate, and helpful for skill development and attitude formation. Parents must not make children feel bad for coming out with such questions about sexuality. As guides, parents must treat every question of the child with respect and sensitivity. It is only when this is done that children will trust their parents.

The content of the CSE must match the developmental age of the child or pupil. At the curriculum designing and development stage, experts from multi-disciplines (i.e., child psychology, theology, pedagogy, traditional leaders; parents; and legal experts) must sit together to design a CSE curriculum that meets the needs of the child, educational goals of the country, and the cultural values and norms of the community.

Change does not happen overnight; it requires negotiation, structures and gradual implementations. A full brown CSE curriculum of Western societies cannot be implemented, hook, line and sink in the Ghanaian context since each context has unique socio-cultural realities. Because most Ghanaian adults were taught the indigenous curriculum on human sexuality, they do not entirely understand what CSE is about. It would be appropriate to organize civic education and community-based workshops as well as media programs for the

\footnotetext{
48 UNESCO, International Technical Guidance on Sexuality Education: An Evidence-Informed Approach for Schools, Teachers and Health Educators, (Paris: UNESCO, 2009)

49 World Health Organization, Standards for Sexuality Education in Europe: A Framework for Policy Makers, Educational and Health Authorities and Specialists. (San Francisco: WHO, 2010). Accessed May 21, 2021 from http://www.bzgawhocc.de/pdf.php?id=061a863a0fdf28218e4fe9e1b3f463b3>
} 
average Ghanaian parent to appreciate the problems confronting nations as a result of sexuality crises. Through such workshops and media programs, their questions, fears, and views can be sampled and considered when implementing the CSE curriculum in schools. These programs should include the participation of religious leaders, traditional leaders, opinion members, role models of the Ghanaian community, child rights experts as well as developmental psychologists.

The general position of the Tutu-Akuapem people is that Ghana must not uncritically absorb what appears to the disguised ideological scheme. Hasty implementation of a Western drafted CSE curriculum would supplant those cherished cultural norms, values, and expressions of sexuality that make the Ghanaian different from the Westerner. A team of experts from all stakeholders must be put together to look at the best content for CSE education for Ghanaian schools. In doing so, traditional and religious leaders, child right activists, representatives from the Ministry of Gender and Children Affairs, Education, Culture and Religion, as well as, purposively sampled adults must be brought together at a table to discuss, deliberate, confer, and develop a CSE curriculum that reflects the educational, social, and developmental aspirations of the country. Ghanaian educational experts, curriculum designers, policymakers, and even social activists who are extremely skewed to western ideologies and worldviews must admit their biases on indigenous norms and rites of sexuality.

\title{
CONCLUSION
}

The reported story below situates the value judgements of the researchers on the need for balanced CSE respectable of the cultural context, norms and values of the particular societies.

\begin{abstract}
A six-year-old boy and his three-year-old sister were found engaging themselves in a playful activity that involved their genitals. Apparently, the girl had removed her dress and underwear and was lying in a sexually horizontal position. As the boy was unzipping his pant and lie on top of the sister, their aunt suddenly entered the room and screamed at them to stop the act. The kids received spontaneous beatings from the aunt. With tears, they went and reported to their mother that "aunty came to beat us while we were playing." They were mute on the kind of 'play' in which they involved themselves.
\end{abstract}

A couple of salient issues and critical questions come into mind when one considers 'the frequency,' 'the degree,' and 'the various modes' of activities through which amoral children exhibit knowledge of sexuality. The kids in the narrative might not have been taught that it is inappropriate to play with each other's genitalia. The parents might have taken it for granted that the kids were too little to experiment or act out what they might have seen on televisions. However, given the numerous fragment of empirical narratives about pre-school and early grade pupils' exhibition of sexuality, the question is: What makes it inappropriate to teach tender children sexuality norms, values, and ideals appropriate to their age level? If they are to be exposed to primary sexuality education, what content is relevant at each stage of pre-school life or the various levels of basic school levels?

Contrary to the emotive notions that parents, traditional and religious leaders hold about sexuality education of kids, children, and adolescents, the above story drives home the point that pieces of well-thoughtout education on basic facts and norms of sexuality are invaluable to the personality development of the child. Although the home is the foremost context of sexuality education, the authors argue that the school should be accorded as the best conduit to disseminate information about children and adolescent development, particularly their psychological, emotional, physical and social development. CSE is capable of demystifying and desensationalising sexuality among adolescents, and the entire community about varied sexuality issues. It can equip young people with knowledge, skills, attitudes, and values relevant for making lifechanging decisions about their sexual health and overall well-being. Hence, it is recommended that the people of Tutu Akuapem must create a compromise between the indigenous curriculum and the formal educational curriculum on sexuality education to bring about comprehensive literacy to the children, adolescents, and adults in ways and modes that guarantee the essential cultural ideals of the community. It is only through such a calculated compromise that society can preserve the relevance of its indigenous beliefs on sexuality. Otherwise, in the space of time, the tides of globalisation, growing activism for absolute freedom of sexual preferences and expression, and mass media influences would uproot into the deep seas the very indigenous ideals on human sexuality, which forms a unique aspect of the African's identity. 


\section{ABOUT AUTHORS}

Solomon Kwame Gyamerah is a PhD student at the Department of Arts Education, University of Cape Coast. He holds a B.Ed, Bachelor of Divinity and Master of Philosophy degrees from the University of Education, Winneba - Mampong Ashanti Campus, Trinity Theological Seminary, Legon Accra and the University of Ghana, respectively. He is the Principal of the Methodist College of Education, Akyem Asene-Aboabo, OdaEastern Region - Ghana. He is also an ordained minister of the Methodist Church of Ghana and currently the minister-in-charge of Bethel Society - Akim Aboabo of the Oda Diocese.

Maxwell Kojo Tsibu is a PhD candidate at the Department of Religion and Human Values. He holds B.Ed. and Master of Philosophy degrees from the same Department at the University of Cape Coast (UCC). He is a Tutor at the Methodist College of Education, Akyem Asene-Aboabo, Oda- Eastern Region - Ghana.

\section{BIBLIOGRAPHY}

Akrong, Abraham. An African Philosophy of Religion. Ghana, Accra: Trinity Theological Seminary, 2005. Amenga-Etego, Rosemary. Mending the Broken Pieces: Indigenous Religion and Sustainable Rural Development in Ghana. Nairobi, Kenya: Africa World Press, 2011.

American Psychological Association \& National Association of School Psychologists, Resolution on gender and sexual orientation diversity in children and adolescents in schools, 2015. (Accessed June 2, 2021) from http://www.apa.org/about/policy/orientation-diversity.aspx

Anum, Eric. "The Body Matters: Rights and Rites of African Sexualities and the Body in the context of 1Cor. 6." International Journal of Humanities Social Sciences and Education (IJHSSE), 1(8), (2014), 99100.

Appiah, Kofi. Decolonizing Knowledge: Anthropocentrism and Cosmotheandrism in a world of Technologies. Groningen: CounterPoint Navigating Knowledge, 2020, 5.

Awusabo-Asare, K., Melissa Stillman, Sarah Keogh, David Teye Doku, Akwasi Kumi-Kyereme, Kobina Esia-Donkoh, Ellie Leong, Joshua Amo-Adjei \& Akinrinola Bankole. From Paper to Practice: Sexuality Education Policies and their Implementation in Ghana. Guttmacher Institute, 2017. (Accessed May 15, 2021) https://www.guttmacher.org/report/sexuality-education-ghana.

Butler, Judith. Bodies that matter. New York and London: Routledge, 1993.

. Gender Trouble: Feminism and the Subversion of Identity. New York and London: Routledge, 1990.

Creswell, John W. Research Design: Qualitative, Quantitative, and Mixed Methods Approaches. London, UK: Sage Publications Limited, 2010.

Eckert, Penelope and Ginet Sally M. Language and Gender. Cambridge and New York: Cambridge University Press, 2019.

Fausto-Sterling, Anne. Sexing the Body: Gender Politics and the Construction of Sexuality. New York: Basic Books, 2000.

Husserl, Edmund. The Idea of Phenomenology. The Hague, The Netherlands: Nijhoff, 1970.

Hyde, Janet S. and Delamater, John D. Understanding Human Sexuality. United States: McGraw-Hill Companies, 2000.

Koch, Tech. "The Influence of Husserl and Heidegger." Journal of Advanced Nursing, 21 (1995): 827-836.

Nelson, James B. and Sandra Longfellow P. Sexuality and the Sacred: Sources for Theological Reflection. Louisville: Westminster/John Knox Press, 1994.

Oloruntoba-oju, Tawio. "Sexuality Language and Communication in Africa." Sexuality in Africa Magazine \& Monographs, 7(2), (2011): 2.

Pettersson, Olof and Hans, Akerberg. Interpreting Religious Phenomena: Studies with Reference to the Phenomenology of Religion. NY, New York: Atlantic Highlands, 1981.

Polkinghorne, Donald E. Methodology for the Human Sciences: Systems of Inquiry. Albany: State University of New York Press, 1983. 
Prempeh, Akwasi Agyeman, Akanfo 4 Amammer 1: Comprehensive Notes on Oral Literature,

Customs and Institutions for Students In Senior High Schools, Ghana, Kumasi: Print House, May 2011.

Quarcopome, T. O. Nii. West African Traditional Religion. Nigeria, Ibadan: African University Press, 1987.

Thomas, Jones W. The Twentieth Century to Wittgenstein and Sarte. San Francisco: Harcourt Brace Jovanovich, 1975.

UNESCO. "Facing the facts: the case for comprehensive sexuality education." UNESCO Policy Paper 39, https://en.unesco.org/gem-report/sites/gem-report/files/CSE_references.pdf . International Technical Guidance on Sexuality Education: An Evidence-Informed Approach for Schools, Teachers and Health Educators. Paris: UNESCO, 2009.

Valle, Ronald, Martin King and Halling Steen. "An Introduction to Existential Phenomenological Thought in Psychology." In Existential-phenomenological perspective in psychology, edited by Ronald Valle \& Steen. Halling, 3-16. New York: Plenum Press, 1989.

West, Candace and Zimmerman Don. "Doing gender." Gender and Society, 1 (2000): 25-151.

World Health Organization, Standards for Sexuality Education in Europe: A Framework for Policy Makers, Educational and Health Authorities and Specialists. San Francisco: WHO, 2010. 